\title{
Triglyceride glucose index is an independent predictor for the progression of coronary artery calcification in the absence of heavy coronary artery calcification at baseline
}

Ki-Bum Won ${ }^{1,2}$, Eun Ji Park ${ }^{3}$, Donghee Han ${ }^{2,4}$, Ji Hyun Lee ${ }^{5}$, Su-Yeon Choi ${ }^{6}$, Eun Ju Chun ${ }^{7}$, Sung Hak Park ${ }^{8}$, Hae-Won Han ${ }^{9}$, Jidong Sung ${ }^{10}$, Hae Ok Jung ${ }^{11}$ and Hyuk-Jae Chang ${ }^{2,12^{*}}$ (1)

\begin{abstract}
Background: Data on the relationship between the triglyceride glucose (TyG) index and coronary artery calcification (CAC) progression is limited. This longitudinal study evaluated the association of TyG index with CAC progression in asymptomatic adults.

Methods: We enrolled 12,326 asymptomatic Korean adults who had at least two CAC evaluations. The TyG index was determined using $\mathrm{ln}$ (fasting triglycerides $[\mathrm{mg} / \mathrm{dL}] \times$ fasting glucose $[\mathrm{mg} / \mathrm{dL}] / 2$ ). CAC progression was defined as a difference $\geq 2.5$ between the square roots $(\sqrt{ })$ of the baseline and follow-up coronary artery calcium score (CACS) $(\Delta \sqrt{ }$ transformed $C A C S)$. Annualized $\Delta \sqrt{ }$ transformed CACS was defined as $\Delta \sqrt{ }$ transformed CACS divided by the interscan period.

Results: During a mean 3.3 years, the overall incidence of CAC progression was 30.6\%. The incidence of CAC progression (group I [lowest]: $22.7 \%$ versus [vs.] group II: $31.7 \%$ vs. group III [highest]: $37.5 \%, P<0.001$ ) and annualized $\triangle \sqrt{ }$ transformed $C A C S$ (group I: $0.46 \pm 1.44$ vs. group II: $0.71 \pm 2.02$ vs. group III: $0.87 \pm 1.75, P<0.001$ ) were markedly elevated with increasing TyG index tertiles. Multivariate linear regression analysis showed that TyG index was associated with annualized $\triangle \sqrt{ }$ transformed $C A C S(\beta=0.066, P=0.036)$. In multivariate logistic regression analysis, the TyG index was significantly associated with CAC progression in baseline CACS $\leq 100$.
\end{abstract}

Conclusion: The TyG index is an independent predictor of CAC progression, especially in adults without heavy baseline CAC.

Keywords: Triglyceride glucose index, Insulin resistance, Coronary artery calcification, Atherosclerosis

*Correspondence: hjchang@yuhs.ac

${ }^{12}$ Division of Cardiology, Severance Cardiovascular Hospital, Yonsei-Cedars-Sinai Integrative Cardiovascular Imaging Research Center, Yonsei University College of Medicine, Yonsei University Health System, 50-1 Yonsei-ro, Seodaemun-gu, Seoul 03722, South Korea

Full list of author information is available at the end of the article

\section{Background}

Recent epidemiologic study revealed that the number of people who died from cardiovascular (CV) disease in 2013 was more than 17.3 million, representing an increase from 1990 of 40.8\% [1]. The progression of atherosclerosis-related CV disease (ASCVD) is strongly associated with the risk of $\mathrm{CV}$ morbidity and mortality. Coronary artery calcification (CAC) is an effective marker for ASCVD and predicts adverse clinical

c) The Author(s) 2020. This article is licensed under a Creative Commons Attribution 4.0 International License, which permits use, sharing, adaptation, distribution and reproduction in any medium or format, as long as you give appropriate credit to the original author(s) and the source, provide a link to the Creative Commons licence, and indicate if changes were made. The images or other third party material in this article are included in the article's Creative Commons licence, unless indicated otherwise in a credit line to the material. If material is not included in the article's Creative Commons licence and your intended use is not permitted by statutory regulation or exceeds the permitted use, you will need to obtain permission directly from the copyright holder. To view a copy of this licence, visit http://creativeco mmons.org/licenses/by/4.0/. The Creative Commons Public Domain Dedication waiver (http://creativecommons.org/publicdomain/ zero/1.0/) applies to the data made available in this article, unless otherwise stated in a credit line to the data. 
outcomes [2-4]. Thus, CV risk is commonly assessed by the coronary artery calcium score (CACS), which is determined by computed tomography. In addition to baseline CACS and conventional CV risk factors, CAC progression is known as a powerful predictor of mortality [5].

The triglyceride glucose (TyG) index has been suggested as a reliable surrogate marker of insulin resistance (IR), which is a substantial risk factor for ASCVD [6-9]. Previous studies reported that TyG index is significantly associated with an increased risk of developing type 2 diabetes, hypertension, and adverse CV events [10-14]. In addition, several cross-sectional studies identified the strong relation between the TyG index and atherosclerosis in different clinical conditions [15-21]. However, data on the association of TyG index with CAC change in asymptomatic adults is limited. Especially, the significance of TyG index on CAC progression based on baseline CAC status has not been evaluated in a large population. Therefore, in the present study, we evaluated the association between the TyG index and CAC progression in asymptomatic 12,326 Korean adults.

\section{Methods}

\section{Study population and design}

Data from the Korea Initiatives on Coronary Artery Calcification (KOICA) registry were analysed in the present study. Briefly, the KOICA is a retrospective, multicentre, and observational registry with single ethnicity in the setting of self-referral for asymptomatic subjects who underwent general health examination at six healthcare centres in South Korea [22]. Overall, 93,707 subjects were enrolled in the KOICA registry from December 2012 to August 2016. Self-reported medical questionnaires were used to obtain information on previous medical history. All data were obtained during visits to each healthcare centre. Among the 93,707 subjects from this registry, 12,326 subjects who underwent at least two CAC scan examinations with available data on the TyG index and diabetic status were finally included in the present study.

\section{Data collection}

Information on history of hypertension, diabetes, hyperlipidaemia, and smoking status for each subject was systematically collected. Weight, height, and blood pressure were measured during the healthcare centre visits. Weight and height were measured during the subjects wore light clothing without shoes. The body mass index was calculated as weight $(\mathrm{kg}) /$ height $\left(\mathrm{m}^{2}\right)$. Blood pressure of the right arm was measured using an automatic manometer after resting for at least more than $5 \mathrm{~min}$. All blood samples including total cholesterol, triglyceride, high-density lipoprotein cholesterol (HDL-C), low-density lipoprotein cholesterol (LDL-C), creatinine, glucose, and glycated haemoglobin A1C (HbA1C) levels were obtained after at least $8 \mathrm{~h}$ of fasting and analysed. All methods were performed in accordance with the relevant guidelines and regulations.

\section{Ethical statement}

The appropriate institutional review board committees of each centre approved the protocol of present study.

\section{Definitions}

Hypertension was defined as systolic blood pressure $\geq 140 \mathrm{mmHg}$ or diastolic blood pressure $\geq 90 \mathrm{mmHg}$, a previous diagnosis of hypertension, or use of anti-hypertensive medication [23]. Hyperlipidaemia was defined as a total cholesterol level of $\geq 240 \mathrm{mg} /$ $\mathrm{dL}$ or anti-hyperlipidemic treatment. Diabetes was defined as either a fasting glucose level $\geq 126 \mathrm{mg} / \mathrm{dL}$, HbA1C level $\geq 6.5 \%$, a referral diagnosis of diabetes, or use of anti-diabetic treatment [24]. Current smoking history was considered present if subjects currently smoked or smoked until 1 month before the study. The TyG index was determined using $\ln$ (triglycerides $[\mathrm{mg} / \mathrm{dL}] \times$ glucose $[\mathrm{mg} / \mathrm{dL}] / 2)$. All participants were categorised into three groups based on the tertile of the TyG index level.

CACS was measured based on the scoring system, as previously described by Agatston et al. [25]. CAC progression was defined as a difference $\geq 2.5$ between the square roots $(\sqrt{ })$ of the baseline and follow-up CACSs $(\Delta \sqrt{ }$ transformed CACS) considering inter-scan variability [26]. Annualised $\Delta \sqrt{ }$ transformed $C A C S$ was defined as $\Delta \sqrt{ }$ transformed $C A C S$ divided by the inter-scan period. All computed tomography (CT) scans used to assess CAC were obtained from a $>16$-slice multi-detector CT scanner (GE 64-slice Lightspeed, Siemens 16-slice Sensation, Philips Brilliance $256 \mathrm{iCT}$, and Philips Brilliance 40-channel multi-detector CT). All centres performed standard prospective or retrospective methods.

\section{Statistical analysis}

Continuous variables are expressed as the mean \pm standard deviation. Categorical variables are presented as absolute values and proportions. After checking the distribution status of variables, the one-way analysis of variance test was used to analyse continuous variables and the $\chi^{2}$ or Fisher's exact test was used to analyse categorical variables, as appropriate. Multivariate linear regression analysis was used for the association of clinical variables with annualized $\Delta \sqrt{ }$ transformed CACS in overall participants. Multivariate logistic regression analysis was performed to identify independent predictors for CAC progression according to categorical baseline CACS. All statistical analyses were performed using 
the Statistical Package for the Social Sciences version 19 (SPSS, Chicago, Illinois) and SAS version 9.1.3 (SAS Institute Inc., Cary, North Carolina). A P-value $<0.05$ was considered significant in all analyses.

\section{Results}

\section{Baseline characteristics}

The mean age of the 12,326 participants $(10,382$ men, $84.2 \%)$ was $51.7 \pm 8.5$ years. The prevalence of hypertension, diabetes, hyperlipidaemia, and current smoking was $33.5 \%, 13.8 \%, 28.0 \%$, and $28.5 \%$, respectively. The ranges of the TyG index in stratified groups of I (lowest), II, and III (highest) were 6.77-8.40, 8.41-8.91, and 8.92-11.62, respectively. Systolic and diastolic blood pressure; body mass index (BMI); the levels of total cholesterol, triglyceride, LDL-C, glucose, HbA1C, and creatinine; and the prevalence of male sex, hypertension, diabetes, hyperlipidaemia, and current smoking significantly increased with increasing TyG index tertiles. In contrast, the mean age and HDL-C levels significantly decreased with increasing tertiles (Table 1).

\section{Baseline and change of CAC}

At baseline, overall prevalence of CACA 0, 1-10, 11-100, and $>100$ was $56.2 \%, 13.9 \%, 19.3 \%$, and $10.6 \%$, respectively. According to the TyG index tertiles, the mean CACSs were $36.8 \pm 153.9,50.8 \pm 174.4$, and $50.0 \pm 186.1$ in group I, group II, and group III, respectively. The significant difference in the proportion of categorical CACS among the three groups was observed (Fig. 1). During the mean inter-scan period of $3.3 \pm 1.8$ years, the overall incidence of CAC progression was $30.6 \%$. The incidence of CAC progression (group I: $22.7 \%$ versus [vs.] group II: $31.7 \%$ vs. group III: $37.5 \%, P<0.001), \Delta \sqrt{ }$ transformed

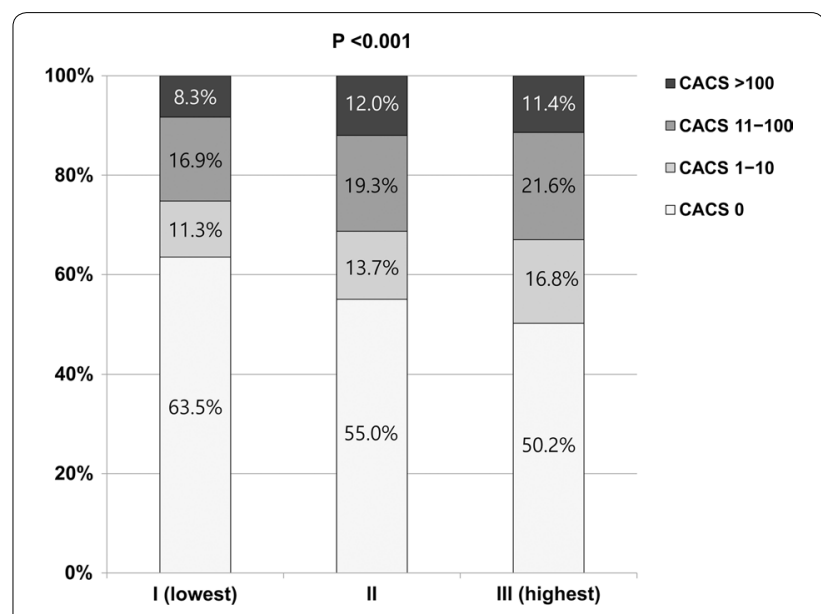

Fig. 1 Comparison of baseline coronary artery calcification according to triglyceride glucose index tertiles. CACS coronary artery calcium scores

Table 1 Clinical characteristics of the study cohort

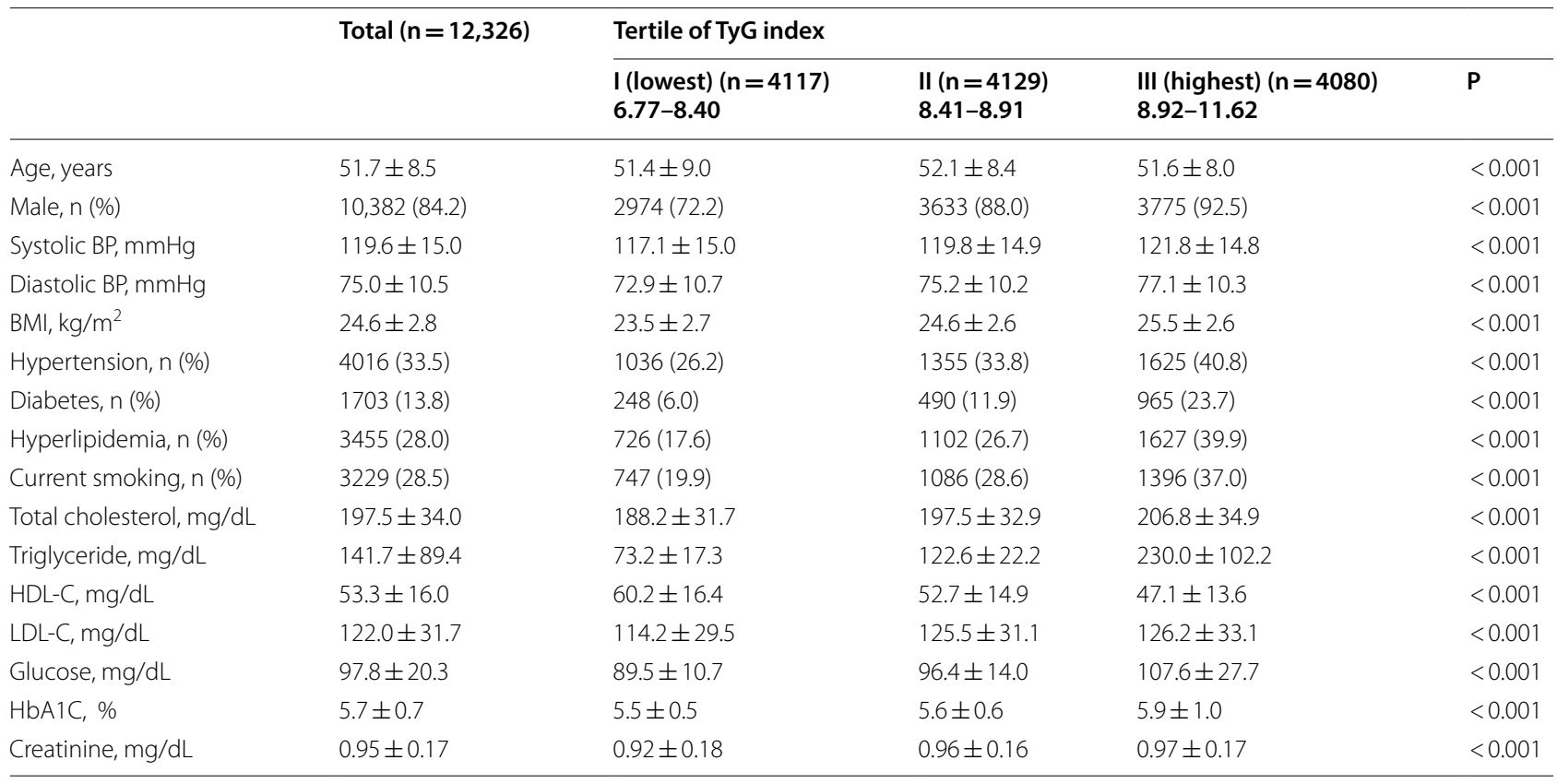

Values are presented as the mean \pm standard deviation or number (\%)

$B M I$ body mass index, BP blood pressure, HbA1C glycated haemoglobin A1C, HDL-C high-density lipoprotein cholesterol, LDL-C low-density lipoprotein cholesterol, TyG triglyceride glucose 
CACS (group I: $1.65 \pm 3.95$ vs. group II: $2.52 \pm 4.85$ vs. group III: $3.09 \pm 5.21, \mathrm{P}<0.001)$, and annualised $\Delta \sqrt{ }$ transformed CACS (group I: $0.46 \pm 1.44$ vs. group II: $0.71 \pm 2.02$ vs. group III: $0.87 \pm 1.75, \mathrm{P}<0.001$ ) were elevated with increasing TyG index tertiles (Fig. 2).

\section{TyG index and CAC change in each categorical CACS}

The incidence of CAC progression was elevated with increasing TyG index tertiles in categorical CACSs of $0,1-10,11-100$, and $>100$ (CACS $0: 8.6 \%$ vs. $13.4 \%$ vs. $18.1 \%, \mathrm{P}<0.001$; CACS $1-10: 52.3 \%$ vs. $57.1 \%$ vs. $61.2 \%, \mathrm{P}<0.001$; CACS $11-100: 44.3 \%$ vs. $51.9 \%$ vs. $54.2 \%, \mathrm{P}<0.001$; $\mathrm{CACS}>100$ : $46.0 \%$ vs. $53.6 \%$ vs. $55.7 \%, \mathrm{P}=0.020)$. Annualised $\Delta \sqrt{ }$ transformed CACS was elevated with increasing TyG index tertiles in categorical CACSs of $0(0.13 \pm 0.48$ vs. $0.21 \pm 0.56$ vs. $0.29 \pm 0.85, \mathrm{P}<0.001), 1-10(0.89 \pm 1.07$ vs. $1.06 \pm 1.26$ vs. $1.20 \pm 1.24, \mathrm{P}<0.001)$, and $11-100(1.17 \pm 1.87$ vs. $1.54 \pm 2.30$ vs. $1.64 \pm 2.26, \mathrm{P}<0.001)$, not in CACS $>100$ $(0.93 \pm 3.51$ vs. $1.25 \pm 4.44$ vs. $1.45 \pm 2.93, \mathrm{P}=0.143)$ (Fig. 3).

\section{Association between clinical variables and CAC change}

Multivariate linear regression analysis showed that age, male sex, hypertension, diabetes, hyperlipidaemia, obesity, current smoking, creatinine, TyG index, and baseline CACS $>100$ were associated with annualized $\Delta \sqrt{ }$ transformed CACS (All $\mathrm{P}<0.05$ ) (Table 2). The result of multivariate logistic regression analysis for the association between clinical variables and $\mathrm{CAC}$ progression was described in Additional file 1: Table S1.

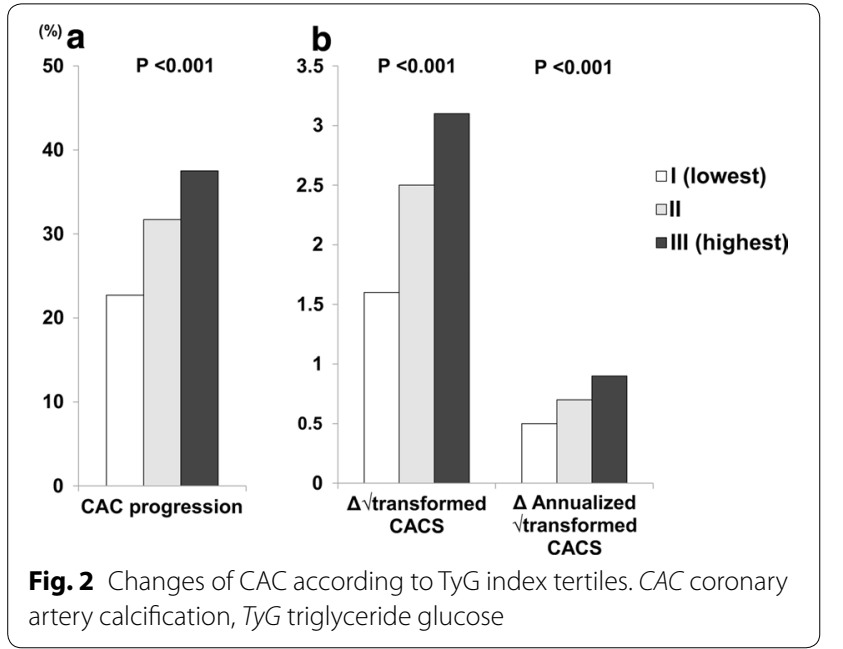

Fig. 2 Changes of CAC according to TyG index tertiles. CAC coronary artery calcification, $T y G$ triglyceride glucose
Table 2 Association of clinical variables with annualized $\Delta \sqrt{ }$ transformed CACS

\begin{tabular}{llll}
\hline Variables & $\boldsymbol{\beta}$ & SE & P \\
\hline Age, pre-1 year increase & 0.032 & 0.002 & $<0.001$ \\
Male & 0.281 & 0.055 & $<0.001$ \\
Hypertension & 0.255 & 0.037 & $<0.001$ \\
Diabetes & 0.334 & 0.050 & $<0.001$ \\
Hyperlipidemia & 0.168 & 0.037 & $<0.001$ \\
Obesity & 0.113 & 0.035 & 0.001 \\
Current smoking & 0.146 & 0.037 & $<0.001$ \\
Creatinine, per-1 mg/dL increase & 0.357 & 0.111 & 0.001 \\
TyG index, per-1 increase & 0.066 & 0.031 & 0.036 \\
Baseline CACS $>100$ & 0.230 & 0.057 & $<0.001$ \\
\hline BMIbody mass index, CACS coronary ater calum scor TyGtiglyceide
\end{tabular}

$B M I$ body mass index, CACS coronary artery calcium score, Ty $G$ triglyceride glucose
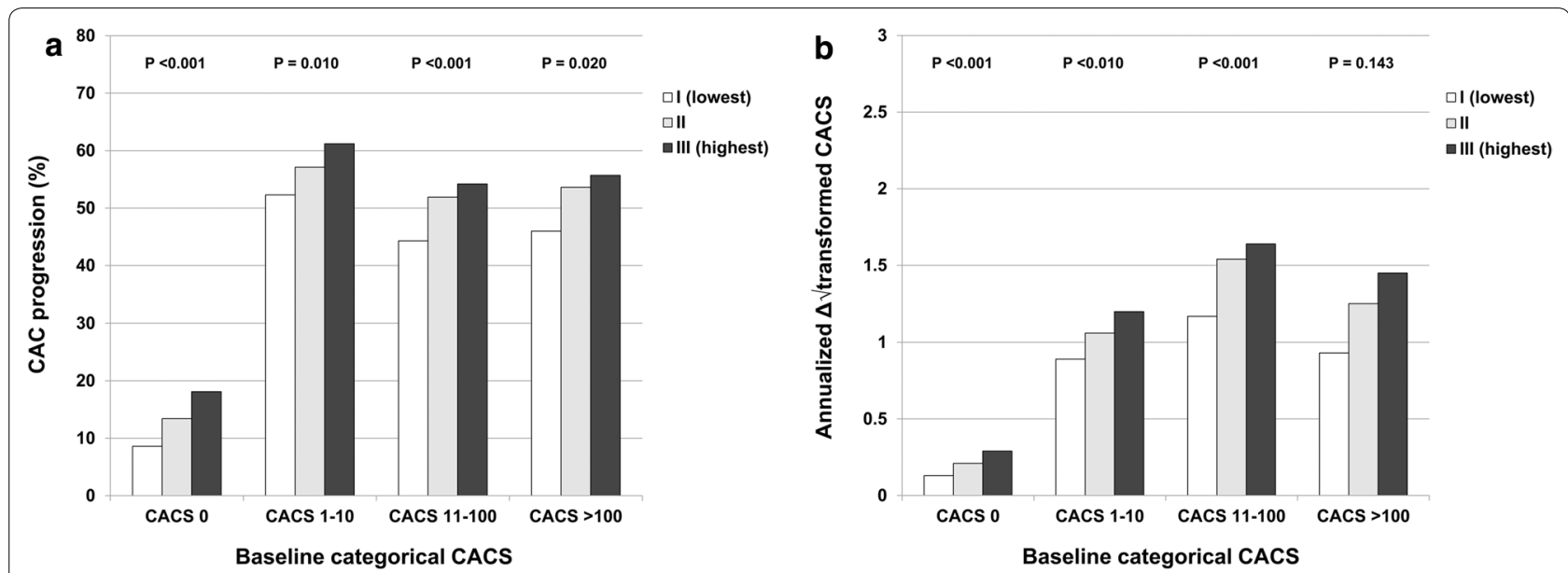

Fig. 3 Changes of CAC according to the baseline CACS. CAC coronary artery calcification, CACS coronary artery calcium score 


\section{TyG index and the risk of CAC progression according} to the baseline CACS

With regards to the relation of TyG index with CAC progression according to the baseline CACS, the TyG index (per 1-unit increase) was associated with an increased risk of CAC progression in baseline CACSs of $0,1-10$, and 11-100 after adjusting for age, male sex, BMI, hypertension, diabetes, hyperlipidaemia, current smoking, and serum creatinine level. However, this association of the TyG index and CAC progression was not observed in the condition with baseline CACS > 100 (Table 3). After adjusting for age, male sex, BMI, systolic and diastolic BP, the level of total cholesterol, triglyceride, HDL-C, LDL$\mathrm{C}$, glucose, and creatinine, and current smoking, the relation of TyG index and CAC progression was consistent (Additional file 2: Table S2).

\section{Discussion}

The present study aimed to evaluate longitudinal change of CAC related to TyG index after considering baseline CAC status in asymptomatic adults. A number of studies reported that the TyG index was related to the risk of developing traditional CV disease and adverse clinical events. Recent cross-sectional data from Brazilian Cardioprotective Nutritional Program Trial showed the positive association of TyG index with metabolic and behavioral risk factors [27]. In the present study, we identified that the incidence of CAC progression was elevated with an increasing TyG index irrespective of baseline CACS in this study. A remarkable result was that high TyG index was significantly associated with an increased

Table 3 Impact of the TyG index (per 1-unit increase) on CAC progression based on baseline categorical CACS

\begin{tabular}{ccrcr}
\hline & OR (95\% Cl) & P & RR (95\% Cl) & P \\
\hline CACS 0 & & & & \\
Model 1 & $1.83(1.63-2.05)$ & $<0.001$ & $1.67(1.52-1.82)$ & $<0.001$ \\
Model 2 & $1.37(1.18-1.59)$ & $<0.001$ & $1.30(1.15-1.46)$ & $<0.001$ \\
CACS 1-10 & & & & \\
Model 1 & $1.39(1.17-1.65)$ & $<0.001$ & $1.15(1.07-1.23)$ & $<0.001$ \\
Model 2 & $1.28(1.05-1.57)$ & 0.016 & $1.11(1.02-1.20)$ & 0.014 \\
CACS 11-100 & & & & \\
Model 1 & $1.42(1.24-1.64)$ & $<0.001$ & $1.18(1.11-1.26)$ & $<0.001$ \\
Model 2 & $1.34(1.14-1.59)$ & 0.001 & $1.15(1.06-1.24)$ & $<0.001$ \\
CACS > 100 & & & & \\
Model 1 & $1.33(1.09-1.62)$ & 0.004 & $1.14(1.04-1.24)$ & 0.003 \\
Model 2 & $1.04(0.83-1.31)$ & 0.743 & $1.02(0.92-1.14)$ & 0.702 \\
\hline
\end{tabular}

Models: 1 = unadjusted; 2 = adjusted for age, male sex, BMI, hypertension, diabetes, hypercholesterolemia, current smoking, and serum creatinine level

$B M I$ body mass index, $C A C$ coronary artery calcification, $C A C S$ coronary artery calcium score, $\mathrm{Cl}$ confidence interval, $O R$ odds ratio, $R R$ relative risk, $T y G$ triglyceride glucose risk of CAC progression in subjects who had baseline CACS $\leq 100$ after adjusting for traditional risk factors.

The homeostatic model assessment of IR (HOMA-IR) has been traditionally used to measure IR [28, 29]. However, it is required to measure insulin levels for calculating the HOMA-IR. Considering that insulin levels are not usually achieved during general health check-up in South Korea, calculating the HOMA-IR to estimate IR is somewhat inconvenient for this population. A number of previous studies identified that the TyG index is closely correlated with the HOMA-IR [9, 30]. Moreover, recent data reported that the value of the TyG index predicting IR was better than that of the HOMA-IR $[8,31]$. Based on these evidences, TyG index has been considered as a simple and useful surrogate marker of IR in clinical practice.

Although several cross-sectional studies previously reported a significant relationship between the TyG index and CAC prevalence, longitudinal data have been limited in clinical practice. Recently, Park et al. observed that an elevated TyG index was related to an increased risk of CAC progression in 1175 subjects [32]; however, they evaluated the impact of the TyG index on CAC progression without consideration of the subjects' baseline CACS. Atherosclerosis-related major $\mathrm{CV}$ events commonly occur even among subjects with low CV risk burden [33, 34]. The Multi-Ethnic Study of Atherosclerosis study suggested that the CACS was a strong predictor of adverse clinical outcomes and provided clinical information beyond traditional CV risk factors [4]. In particular, Blaha et al. reported excellent prognosis in the absence of CAC in 44,052 consecutive asymptomatic subjects during a mean follow-up of $5.6 \pm 2.6$ years [35]. Considering the incremental impact of CAC progression on an adverse clinical outcome [5], it is a substantial issue to identify independent predictors for CAC progression in clinical practice.

In the current study, $\mathrm{CAC}$ progression was observed in $13.0 \%$ of participants without CAC at baseline. Importantly, we found that a high TyG index has a strong association with an increased risk of CAC progression in this population after adjusting for confounding clinical factors. This relation of the TyG index with CAC progression was consistent in the baseline conditions of CACS of 1-10 and 11-100. However, there was no significant impact of the TyG index on CAC progression in participants with baseline CACS $>100$. This result might be affected by the relatively small sample size of participants with CACS $>100$, which was about $10.6 \%$ in our study. Thus, the significance of the TyG index for predicting CAC progression is still uncertain in individuals with heavy calcification at baseline. Further prospective studies with a large sample size are necessary to confirm this issue. 
The mechanism underlying the relationship of the TyG index with atherosclerosis is unclear. However, previous studies revealed the pivotal role of IR in atherosclerosis progression via promoting apoptosis of macrophages, endothelial cells, and vascular smooth muscle cells [3638]. Recently, data from Coronary Artery Risk Development in Young Adults (CARDIA) study revealed that transitions in metabolic risk occurred early in life and metabolic dysfunction is related to subclinical cardiovascular phenotypes including CAC and myocardial hypertrophy and dysfunction [39]. Park et al. suggested that TyG index was an effective marker for early detecting subclinical coronary atherosclerosis even in the absence of traditional CV risk factors [40]. However, considering the inconsistent results for the association of metabolic syndrome with ASCVD in diabetic patients [41, 42], further large prospective investigation for the clinical significance of TyG index in established diabetes should be necessary in diverse ethnic population.

There are some limitations to the present study. First, the KOICA registry was based on a relatively healthy population who underwent health check-ups in healthcare centres. The present study only included subjects who experienced at least two CAC scan examinations with available data on the TyG index and diabetic status from the KOICA registry. Thus, this study could not represent the characteristics of overall participants of KOICA registry and a potential selection bias might be present. Second, this was a retrospective study, which may be affected by unidentified confounders. Third, we only evaluated the association between the baseline TyG index and CAC progression; however, the mean change of the TyG index was very small: $-0.02 \pm 0.48$. Longitudinal consecutive changes of the TyG index during follow-up could not be confirmed. Fourth, the homeostatic model assessment of IR was not analysed because insulin levels were not measured in the KOICA registry. Fifth, some important data including physical activity, alcohol consumption, family history of disease were unavailable. Sixth, we could not control the effect of medications for hypertension, diabetes, and hyperlipidaemia on CAC progression because of the observational study design. Finally, the present study included only the Korean population. However, this study is unique in that we identified the predictive value of the TyG index for CAC progression according to the baseline CAC status in a large sample of asymptomatic adults.

\section{Conclusion}

The TyG index is strongly associated with CAC progression after adjusting for confounding clinical variables, especially in adults without heavy $\mathrm{CAC}$ at baseline.

\section{Supplementary information}

Supplementary information accompanies this paper at https://doi. org/10.1186/s12933-020-01008-5.

Additional file 1: Table S1. Association between clinical variables and CAC progression.

Additional file 2: Table S2. TyG index (per 1-unit increase) and the risk of CAC progression according to baseline CACS 100.

\section{Abbreviations}

ASCVD: Atherosclerosis-related cardiovascular disease; BMI: Body mass index; CV: Cardiovascular; CAC: Coronary artery calcification; CACS: Coronary artery calcium score; Cl: Confidence interval; HbA1C: Hemoglobin A1C; HDL-C: Highdensity lipoprotein cholesterol; KOICA: Korea Initiatives on Coronary Artery Calcification; LCL-C: Low-density lipoprotein cholesterol; OR: Odds ratio; RR: Relative risk; TyG: Triglyceride glucose.

\section{Acknowledgements \\ None.}

\section{Authors' contributions}

All authors have made substantial contributions. KBW, EJP, and HJC performed the statistical analysis. KBW drafted the manuscript. DH, JHL SYC, EJC, SHP, $\mathrm{HWH}, \mathrm{JS}, \mathrm{HOJ}$, and HJC contributed to data acquisition. KBW and HJC contributed to the interpretation of data. HJC critically revised the manuscript. All authors also gave final approval and agree to be accountable for all aspects of work ensuring integrity and accuracy. All authors read and approved the final manuscript.

\section{Funding}

This work was supported by a Grant from the Korean Health Technology R\&D Project, Ministry of Health and Welfare, Republic of Korea (HI13C0715).

\section{Availability of data and materials}

The datasets used and analyzed during the current study are available from the corresponding author on reasonable request.

Ethics approval and consent to participate

The study protocol was approved by our institution's ethics committee, and informed consent for the procedure was obtained from each participant.

\section{Consent for publication \\ Not applicable.}

\section{Competing interests}

The authors declare that they have no competing interests.

\section{Author details}

${ }^{1}$ Division of Cardiology, Ulsan University Hospital, University of Ulsan College of Medicine, Ulsan, South Korea. ${ }^{2}$ Division of Cardiology, Severance Cardiovascular Hospital, Yonsei University College of Medicine, Yonsei University Health System, Seoul, South Korea. ${ }^{3}$ Medical Information Center, Ulsan University Hospital, Ulsan, South Korea. ${ }^{4}$ Division of Cardiology, New York-Presbyterian Hospital and Weill Cornell Medical College, New York, NY, USA. ${ }^{5}$ Division of Cardiology, Myongji Hospital, Ilsan, South Korea. ${ }^{6}$ Division of Cardiology, Healthcare System Gangnam Center, Seoul National University Hospital,

Seoul, South Korea. ${ }^{7}$ Division of Radiology, Seoul National University Bundang Hospital, Seongnam, South Korea. ${ }^{8}$ Division of Radiology, Gangnam Heartscan Clinic, Seoul, South Korea. ${ }^{9}$ Department of Internal Medicine, Gangnam Heartscan Clinic, Seoul, South Korea. ${ }^{10}$ Division of Cardiology, Heart Stroke $\&$ Vascular Institute, Samsung Medical Center, Seoul, South Korea. ${ }^{11}$ Division of Cardiology, Seoul St. Mary's Hospital, College of Medicine, The Catholic University of Korea, Seoul, South Korea. ${ }^{12}$ Division of Cardiology, Severance Cardiovascular Hospital, Yonsei-Cedars-Sinai Integrative Cardiovascular Imaging Research Center, Yonsei University College of Medicine, Yonsei University Health System, 50-1 Yonsei-ro, Seodaemun-gu, Seoul 03722, South Korea. 
Received: 26 October 2019 Accepted: 26 February 2020

Published online: 16 March 2020

\section{References}

1. Roth GA, Forouzanfar MH, Moran AE, Barber R, Nguyen G, Feigin VL, Naghavi M, Mensah GA, Murray CJ. Demographic and epidemiologic drivers of global cardiovascular mortality. N Engl J Med. 2015;372(14):1333-41.

2. Wong ND, Hsu JC, Detrano RC, Diamond G, Eisenberg H, Gardin JM. Coronary artery calcium evaluation by electron beam computed tomography and its relation to new cardiovascular events. Am J Cardiol. 2000;86(5):495-8.

3. Budoff MJ, Shaw LJ, Liu ST, Weinstein SR, Mosler TP, Tseng PH, Flores FR, Callister TQ, Raggi P, Berman DS. Long-term prognosis associated with coronary calcification: observations from a registry of 25,253 patients. J Am Coll Cardiol. 2007;49(18):1860-70.

4. Detrano R, Guerci AD, Carr JJ, Bild DE, Burke G, Folsom AR, Liu K, Shea S, Szklo M, Bluemke DA, O'Leary DH, Tracy R, Watson K, Wong ND, Kronma RA. Coronary calcium as a predictor of coronary events in four racial or ethnic groups. N Engl J Med. 2008;358(13):1336-45.

5. Budoff MJ, Hokanson JE, Nasir K, Shaw LJ, Kinney GL, Chow D, Demoss D, Nuguri V, Nabavi V, Ratakonda R, Berman DS, Raggi P. Progression of coronary artery calcium predicts all-cause mortality. JACC CardiovasC Imaging. 2010;3(12):1229-36.

6. Hanley AJ, Williams K, Stern MP, Haffner SM. Homeostasis model assessment of insulin resistance in relation to the incidence of cardiovascular disease: the San Antonio Heart Study. Diabetes Care. 2002;25(7):1177-84.

7. Simental-Mendía LE, Rodríguez-Morán M, Guerrero-Romero F. The product of fasting glucose and triglycerides as surrogate for identifying insulin resistance in apparently healthy subjects. Metab Syndr Relat Disord. 2008;6(4):299-304.

8. Vasques AC, Novaes FS, de Oliveira MS, Souza JR, Yamanaka A, Pareja JC, Tambascia MA, Saad MJ, Geloneze B. TyG index performs better than HOMA in a Brazilian population: a hyperglycemic clamp validated study. Diabetes Res Clin Pract. 2011;93(3):e98-100.

9. Guerrero-Romero F, Villalobos-Molina R, Jiménez-Flores JR, Simental-Mendia LE, Méndez-Cruz R, Murguía-Romero M, Rodríguez-Morán M. Fasting triglycerides and glucose index as a diagnostic test for insulin resistance in young adults. Arch Med Res. 2016;47(5):382-7.

10. Zhang M, Wang B, Liu Y, Sun X, Luo X, Wang C, Li L, Zhang L, Ren Y, Zhao Y, Zhou J, Han C, Zhao J, Hu D. Cumulative increased risk of incident type 2 diabetes mellitus with increasing triglyceride glucose index in normalweight people: the Rural Chinese Cohort Study. Cardiovasc Diabetol. 2017:16(1):30

11. Sánchez-Î̃nigo L, Navarro-González D, Pastrana-Delgado J, FernándezMontero A, Martínez JA. Association of triglycerides and new lipid markers with the incidence of hypertension in a Spanish cohort. J Hypertens. 2016;34(7):1257-65.

12. Sánchez-Iñigo L, Navarro-González D, Fernández-Montero A, PastranaDelgado J, Martínez JA. The TyG index may predict the development of cardiovascular events. Eur J Clin Invest. 2016:46(2):189-97.

13. Mao Q, Zhou D, Li Y, Wang Y, Xu SC, Zhao XH. The triglyceride-glucose index predicts coronary artery disease severity and cardiovascular outcomes in patients with non-ST-segment elevation acute coronary syndrome. Dis Markers. 2019;2019:6891537.

14. Jin JL, Cao YX, Wu LG, You XD, Guo YL, Wu NQ, Zhu CG, Gao Y, Dong QT, Zhang HW, Sun D, Liu G, Dong Q, Li JJ. Triglyceride glucose index for predicting cardiovascular outcomes in patients with coronary artery disease. J Thorac Dis. 2018;10(11):6137-46

15. Kim MK, Ahn CW, Kang S, Nam JS, Kim KR, Park JS. Relationship between the triglyceride glucose index and coronary artery calcification in Korean adults. Cardiovasc Diabetol. 2017:16(1):108.

16. Lee EY, Yang HK, Lee J, Kang B, Yang Y, Lee SH, Ko SH, Ahn YB, Cha BY, Yoon $\mathrm{KH}$, Cho $\mathrm{JH}$. Triglyceride glucose index, a marker of insulin resistance, is associated with coronary artery stenosis in asymptomatic subjects with type 2 diabetes. Lipids Health Dis. 2016;15(1):155

17. Won KB, Kim YS, Lee BK, Heo R, Han D, Lee JH, Lee SE, Sung JM, Cho I, Park $\mathrm{HB}, \mathrm{Cho} \mathrm{IJ}$, Chang HJ. The relationship of insulin resistance estimated by triglyceride glucose index and coronary plaque characteristics. Medicine. 2018;97(21):e10726.

18. Cho YR, Ann SH, Won KB, Park GM, Kim YG, Yang DH, Kang JW, Lim TH, Kim HK, Choe J, Lee SW, Kim YH, Kim SJ, Lee SG. Association between insulin resistance, hyperglycemia, and coronary artery disease according to the presence of diabetes. Sci Rep. 2019;9(1):6129.

19. Won KB, Park GM, Lee SE, Cho IJ, Kim HC, Lee BK, Chang HJ. Relationship of insulin resistance estimated by triglyceride glucose index to arterial stiffness. Lipids Health Dis. 2018:17(1):268.

20. Lee SB, Ahn CW, Lee BK, Kang S, Nam JS, You JH, Kim MJ, Kim MK, Park JS. Association between triglyceride glucose index and arterial stiffness in Korean adults. Cardiovasc Diabetol. 2018;17(1):41.

21. Zhao S, Yu S, Chi C, Fan X, Tang J, Ji H, Teliewubai J, Zhang Y, Xu Y. Association between macro- and microvascular damage and the triglyceride glucose index in community-dwelling elderly individuals: the Northern Shanghai Study. Cardiovasc Diabetol. 2019;18(1):95.

22. Won KB, Han D, Lee JH, Lee SE, Sung JM, Choi SY, Chun EJ, Park SH, Han $\mathrm{HW}$, Sung J, Jung $\mathrm{HO}$, Chang HJ. Impact of optimal glycemic control on the progression of coronary artery calcification in asymptomatic patients with diabetes. Int J Cardiol. 2018:266:250-3.

23. Lawes CM, Rodgers A, Bennett DA, Parag V, Suh I, Ueshima H, MacMahon S. Blood pressure and cardiovascular disease in the Asia Pacific region. J Hypertens. 2003;21(4):707-16.

24. American Diabetes Association. Standards of medical care in diabetes-2014. Diabetes Care. 2014;37(Suppl. 1):S14-80.

25. Agatston AS, Janowitz WR, Hildner FJ, Zusmer NR Jr, Viamonte M, Detrano R. Quantification of coronary artery calcium using ultrafast computed tomography. J Am Coll Cardiol. 1990;15(4):827-32.

26. Hokanson JE, MacKenzie T, Kinney G, Snell-Bergeon JK, Dabelea D, Ehrlich J, Eckel RH, Rewers M. Evaluating changes in coronary artery calcium: an analytical approach that accounts for interscan variability. AJR Am J Roentgenol. 2004;182(5):1327-32.

27. da Silva A, Caldas APS, Hermsdorff HHM, Bersch-Ferreira ÂC, Torreglosa $\mathrm{CR}$, Weber B, Bressan J. Triglyceride-glucose index is associated with symptomatic coronary artery disease in patients in secondary care. Cardiovasc Diabetol. 2019;18(1):89.

28. Wallace TM, Matthews DR. The assessment of insulin resistance in man. Diabet Med. 2002;19(7):527-34.

29. Cutfield WS, Jefferies CA, Jackson WE, Robinson EM, Hofman PL. Evaluation of HOMA and QUICKI as measures of insulin sensitivity in prepubertal children. Pediatr Diabetes. 2003;4(3):119-25.

30. Er LK, Wu S, Chou HH, Hsu LA, Teng MS, Sun YC, Ko YL. Triglyceride glucose-body mass index is a simple and clinically useful surrogate marker for insulin resistance in nondiabetic individuals. PLOS ONE. 2016;11(3):e0149731.

31. Lee SH, Kwon HS, Park YM, Ha HS, Jeong SH, Yang HK, Lee JH, Yim HW, Kang MI, Lee WC, Son HY, Yoon KH. Predicting the development of diabetes using the product of triglycerides and glucose: the Chungju metabolic disease cohort (CMC) study. PLoS ONE. 2014;9(2):e90430.

32. Park K, Ahn CW, Lee SB, Kang S, Nam JS, Lee BK, Kim JH, Park JS. Elevated TyG index predicts progression of coronary artery calcification. Diabetes Care. 2019;42(8):1569-73.

33. Lloyd-Jones DM, Hong Y, Labarthe D, Mozaffarian D, Appel LJ, Van Horn L, Greenlund K, Daniels S, Nichol G, Tomaselli GF, Arnett DK, Fonarow GC, Ho PM, Lauer MS, Masoudi FA, Robertson RM, Roger V, Schwamm LH, Sorlie P, Yancy CW, Rosamond WD. Defining and setting national goals for cardiovascular health promotion and disease reduction: the American Heart Association's strategic Impact Goal through 2020 and beyond. Circulation. 2010;121(4):586-613.

34. Yusuf S, Rangarajan S, Teo K, Islam S, Li W, Liu L, Bo J, Lou Q, Lu F, Liu T, Yu L, Zhang S, Mony P, Swaminathan S, Mohan V, Gupta R, Kumar R, Vijayakumar K, Lear S, Anand S, Wielgosz A, Diaz R, Avezum A, Lopez-Jaramillo P, Lanas F, Yusoff K, Ismail N, lqbal R, Rahman O, Rosengren A, Yusufali A, Kelishadi R, Kruger A, Puoane T, Szuba A, Chifamba J, Oguz A, McQueen M, McKee M, Dagenais G. Cardiovascular risk and events in 17 low-, middle-, and high-income countries. N Engl J Med. 2014;371(9):818-27.

35. Blaha M, Budoff MJ, Shaw LJ, Khosa F, Rumberger JA, Berman D, Callister T, Raggi P, Blumenthal RS, Nasir K. Absence of coronary artery calcification and all-cause mortality. JACC Cardiovasc Imaging. 2009;2(6):692-700.

36. Bornfeldt KE, Tabas I. Insulin resistance, hyperglycemia, and atherosclerosis. Cell Metab. 2011;14(5):575-85. 
37. Sung KC, Wild SH, Kwag HJ, Byrne CD. Fatty liver, insulin resistance, and features of metabolic syndrome: relationships with coronary artery calcium in 10,153 people. Diabetes Care. 2012;35(11):2359-64.

38. Reardon CA, Lingaraju A, Schoenfelt KQ, Zhou G, Cui C, Jacobs-El H, Babenko I, Hoofnagle A, Czyz D, Shuman H, Vaisar T, Becker L. Obesity and insulin resistance promote atherosclerosis through an IFNg-regulated macrophage protein network. Cell Rep. 2018;23(10):3021-30.

39. Murthy VL, Abbasi SA, Siddique J, Colangelo LA, Reis J, Venkatesh BA, Carr JJ, Terry JG, Camhi SM, Jerosch-Herold M, de Ferranti S, Das S, Freedman J, Carnethon MR, Lewis CE, Lima JA, Shah RV. Transitions in metabolic risk and long-term cardiovascular health: coronary artery risk development in young adults (CARDIA) Study. J Am Heart Assoc. 2016;5(10):e003934.

40. Park GM, Cho YR, Won KB, Yang YJ, Park S, Ann SH, Kim YG, Park EJ, Kim SJ, Lee SG, Yang DH, Kang JW, Lim TH, Kim HK, Choe J, Lee SW, Kim YH. Triglyceride glucose index is a useful marker for predicting subclinical coronary artery disease in the absence of traditional risk factors. Lipids Health Dis. 2020;19(1):7.

41. Won KB, Chang HJ, Kim HC, Jeon K, Lee H, Shin S, Cho IJ, Park SH, Lee SH, Jang Y. Differential impact of metabolic syndrome on subclinical atherosclerosis according to the presence of diabetes. Cardiovasc Diabetol. 2013;12:41.

42. Gurka MJ, Guo Y, Filipp SL, DeBoer MD. Metabolic syndrome severity is significantly associated with future coronary heart disease in Type 2 diabetes. Cardiovasc Diabetol. 2018;17:17.

\section{Publisher's Note}

Springer Nature remains neutral with regard to jurisdictional claims in published maps and institutional affiliations.
Ready to submit your research? Choose BMC and benefit from:

- fast, convenient online submission

- thorough peer review by experienced researchers in your field

- rapid publication on acceptance

- support for research data, including large and complex data types

- gold Open Access which fosters wider collaboration and increased citations

- maximum visibility for your research: over $100 \mathrm{M}$ website views per year

At BMC, research is always in progress.

Learn more biomedcentral.com/submissions 